BONPLANDIA 20(2). 2011

ISSN: 0524-0476

\title{
RECURSOS FLORESTAIS NATIVOS E A AGRICULTURA FAMILIAR EM SANTA CATARINA - BRASIL
}

\author{
ALEXANDRE SIMINSKI ${ }^{1}$; KARINE LOUISE DOS SANTOS ${ }^{2}$; ALFREDO CELSO FANTINI ${ }^{3}$ \& MAURÍCIO SEDREZ \\ DOS REIS ${ }^{3}$
}

Summary: Siminski, A., K. L. Santos, A. C. Fantini \& M. S. Reis. Forest Resources on farmer lands in Santa Catarina state - Brazil. Bonplandia 20(2): 371-389.

The use of native forest resources in twentieth century provided the support to occupation and development of the Southern Brazil. Through the interaction with the environment, as a survival strategy, farmers have used these products in order to obtain sustainable production, equipments and income. The goal of this study was to describe the current traditional knowledge about the native species in Santa Catarina state, emphasizing the role of these relations to the conservation of the Atlantic Forest. The database for this study was interviews with 68 farmers, carried out in the three forest types of the State: Seasonal Deciduous Forest (SDF), Mixed Ombrophylous forest (MOF), Dense Ombrophylous forest (DOF). The results revealed 160 species with importance use to the farmers, in the past or current. Were pointed out a similar number of species in different regions (SDF 71, MOF 73 and 79 DOF), distributed mainly in timber (85), medicinal (69), food (28) and ornamental (18) use. The results revealed that these farmers have an extensive local knowledge about the native species, covering a significant part of local flora species.

Key words: Ethonobotany, small farmers, plants resources.

Resumo: Siminski, A., K. L. Santos, A. C. Fantini \& M. S. Reis. Recursos Florestais Nativos e a Agricultura Familiar em Santa Catarina - Brasil. Bonplandia 20(2): 371-389.

O uso dos recursos florestais nativos no século $X X$ marcou a ocupação do território e alavancou o desenvolvimento inicial dos Estados da região Sul do Brasil. No convívio com o ambiente e como estratégia de sobrevivência, os agricultores familiares incorporaram elementos da paisagem florestal à rotina produtiva a fim de obter recursos para o autoconsumo da família, para suprir necessidades de equipamentos e para obter renda. Este estudo teve por objetivo levantar o uso das espécies nativas em Santa Catarina, destacando o seu papel para a conservação dos remanescentes florestais da Mata Atlântica no Estado. A base de dados para este estudo foram entrevistas com 68 agricultores familiares em seis municípios das três tipologias florestais com ocorrência no Estado: Floresta Estacional Decidual (FED), Floresta Ombrófila Mista (FOM), Floresta Ombrófila Densa (FOD). Ao todo foram citadas 160 espécies com importância de uso, no passado ou atual, pelos agricultores. Foram citadas um número similar de espécies nas diferentes regiões (FED 71, FOM 73, e FOD 79), distribuídas principalmente nas categorias de uso madeireiro (85), medicinal (69), alimentício (28) e ornamental (18). Os resultados revelaram que esses agricultores possuem um amplo conhecimento a respeito do potencial de uso das espécies nativas da região, abrangendo parte significativa das espécies da flora local.

Palavras Chave: Etnobotânica, agricultores familiares, recursos florísticos.

${ }^{1}$ Universidade Federal de Santa Catarina - Campus Curitibanos. Núcleo de Pesquisas em Florestas Tropicais. siminski@cbs.ufsc.br

${ }^{2}$ Empresa de Pesquisa Agropecuária e Extensão Rural de Santa Catarina. karinesantos@epagri.sc.gov.br

${ }^{3}$ Universidade Federal de Santa Catarina - Departamento de Fitotecnia. Núcleo de Pesquisas em Florestas Tropicais. afantini@cca.ufsc.br, msedrez@gmail.com 


\section{Introdução}

O uso dos recursos florestais nativos durante o século XX marcou a ocupação do território e alavancou o desenvolvimento inicial dos Estados da região Sul do Brasil, por um processo baseado no aproveitamento imediato das suas riquezas. As florestas eram vistas como um obstáculo à implantação das roças e das pastagens, vocações naturais da terra na concepção do colonizador europeu (Carvalho \& Nodari, 2007; Dalmora, 2004; Santos, 2004).

Apesar desta generalização, no convívio com o ambiente e como estratégia de sobrevivência, os agricultores familiares do Sul do Brasil incorporaram elementos da paisagem florestal à rotina produtiva a fim de obter recursos para o consumo da família, para suprir necessidades de equipamentos e estruturas nas atividades produtivas e para obter renda sazonalmente ou eventualmente (Baldauf \& al., 2007; Caffer, 2005; Fantini, 1999; Siminski, 2004; Vieira da Silva, 2006; Zuchiwschi, 2008).

Neste contexto, muitas práticas de agricultura e pecuária estão inseridas em um sistema de manejo de paisagens, como o realizado nos faxinais (Chang, 1988), e na prática da agricultura de coivara (Peroni \& Martins, 2000; Siminski \& Fantini, 2007), ou no manejo de espécies em ambientes florestais (Baldauf \& al., 2007; Reis, 2006). Estas atividades têm uma relação direta com a conservação dos recursos naturais, quer pela sua dependência da biodiversidade, quer pela necessidade de um ambiente ecologicamente equilibrado para o desenvolvimento agrícola (Berkes \& Folke, 1998; Jain, 2000).

Historicamente, a pressão sobre as áreas florestais do bioma Mata Atlântica e o reconhecimento da ameaça a sua biodiversidade, promoveram, especialmente a partir da década de 80 , mobilizações para a conservação dos seus remanescentes. Essas iniciativas são marcadas por descontinuidades e contradições que pouco auxiliaram na conservação preconizada (Dalmora, 2004), produzindo reduzida satisfação coletiva, principalmente dos proprietários das áreas, com os seus resultados (Siminski, 2009). Em parte, essa insatisfação pode ser atribuída ao ideal de conservação (e/ou preservação) adotado, ainda muito fundamentado no distanciamento dos humanos do restante da natureza (Diegues, 2000).

Neste cenário, as imposições de restrições ao uso de recursos florestais nativos, a falta de alternativas ecologicamente aceitas e o não reconhecimento dos serviços ambientais proporcionado pelos agricultores familiares, por meio de suas florestas, promovem uma lista de razões para que os agricultores não tenham interesse em manter os remanescentes florestais em suas propriedades (Fantini \& Siminski, 2007).

Trabalhos como os de Fantini (1999) e Reis \& al. (2000) têm destacado a possibilidade de se conciliar a conservação dos ecossistemas com alternativas de uso que permitam retorno econômico aos proprietários da terra, através de uma proposta de manejo de populações de forma sustentável. No entanto, muitos dos aspectos do manejo da biodiversidade estão diretamente relacionados à diversidade cultural das pessoas que vivem diretamente em contato com esses recursos e que constroem um conhecimento baseado na combinação dos elementos locais (Guivant, 1997; Jain, 2000). Esse tipo de conhecimento é denominado de conhecimento tradicional, quando se enfoca principalmente o aspecto temporal de sua transmissão ou, conhecimento local, quando o aspecto espacial é mais reforçado (Gadgil \& al., 1993; Guivant, 1997).

O conhecimento tradicional/local, assim como as populações humanas que os detêm, são diversos e dinâmicos e estão constantemente se adaptando, sendo que a limitação na condição de reprodução deste conhecimento, a sua maior ameaça (Hanazaki, 2003). Os conhecimentos que os agricultores familiares do Sul do Brasil possuem, podem contribuir com a conservação ambiental e dependem de condições que permitam a sua aplicação no cotidiano para que continuem existindo e se adaptando às novas condições.

Diante deste contexto, este trabalho objetivou analisar o uso dos recursos florestais em propriedades agrícolas familiares do Estado de Santa Catarina, procurando compreender a relação dos proprietários com as áreas de remanescentes florestais nativos e sobre as possibilidades de seu uso e conservação. 


\section{Material e Métodos}

\section{Local de estudo e Coleta de dados}

Agricultores familiares do Estado de Santa Catarina-Brasil, foram entrevistados entre os meses de Agosto de 2006 a Julho de 2007, com o intuito de obter informações sobre o histórico do uso dos recursos florestais na região, o uso atual da terra e as inter-relações com as áreas de remanescentes florestais. Trabalhou-se em seis municípios, dois em cada uma das formações florestais presentes no estado: Floresta Estacional Decidual (FED) - Anchieta e Concórdia; Floresta Ombrófila Mista (FOM) - Caçador e Três Barras; Floresta Ombrófila Densa (FOD) - Garuva e São Pedro de Alcântara (Fig. 1).
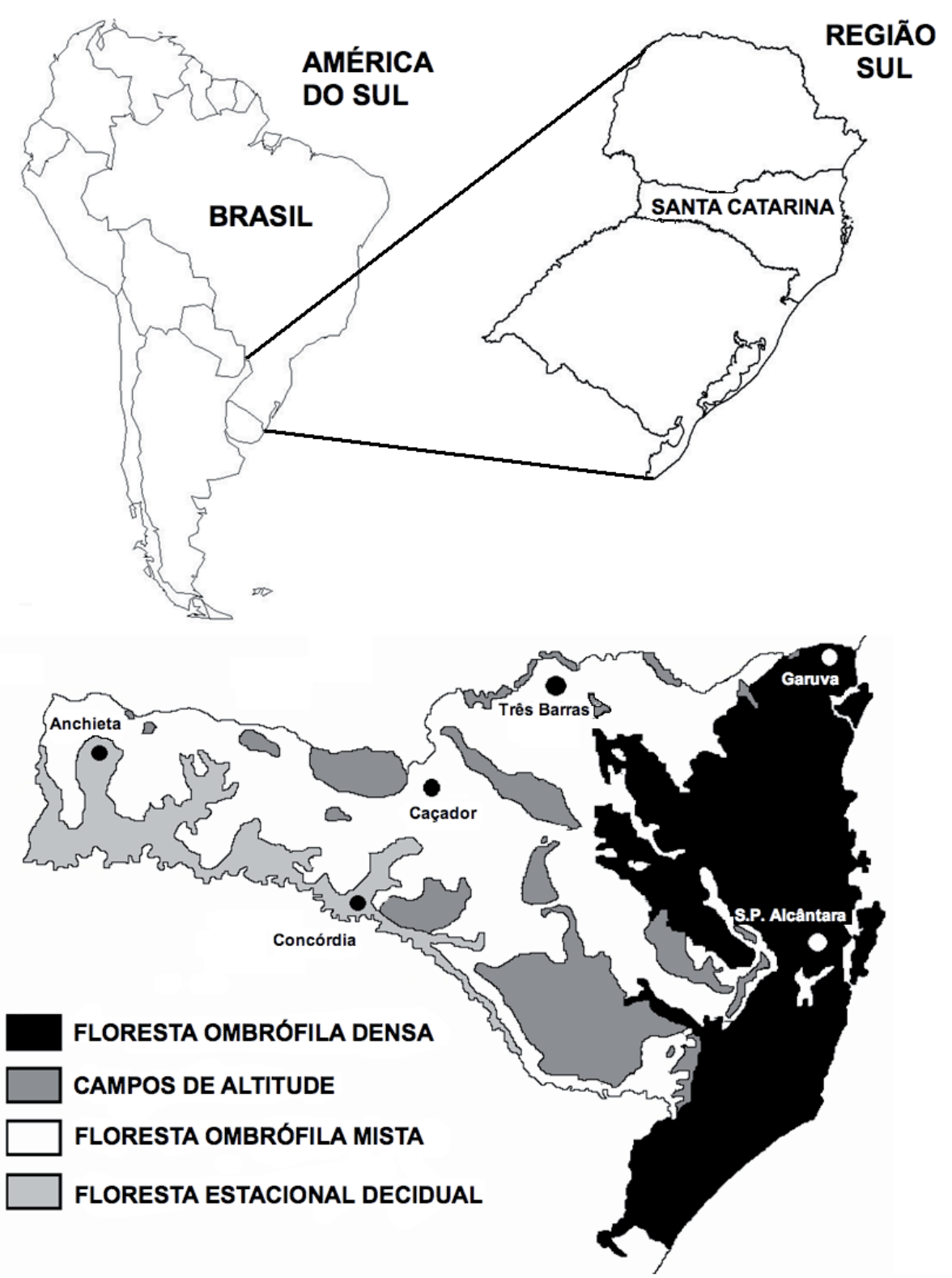

Fig. 1. Localização das áreas de estudo no Mapa fitogeográfico do Estado de Santa Catarina (adaptado de KLEIN, 1978). FOD: Floresta Ombrófila Densa; FOM: Floresta Ombrófila Mista; FED: Floresta Estacional Decidual. 
A seleção dos informantes foi realizada a partir de amostragem intencional (Bernard, 1995), método não probabilístico de escolha de informante, de acordo com as qualidades que possuem e sejam importantes para a pesquisa. Foram realizadas consultas junto a representantes da Epagri (Empresa de Pesquisa Agropecuária e Extensão Rural de Santa Catarina) e facilitadores do Projeto Microbacias $\mathrm{II}^{1}$ nos municípios de Anchieta, Garuva, Três Barras, do Sindicato dos Trabalhadores Rurais de Caçador (Sintruc), da Prefeitura Municipal de São Pedro de Alcântara e da Equipe Co-gestora do Parque Estadual Fritz Plaumann (Ecopef), no município de Concórdia. Essas instituições possuem grande atuação dentro do setor rural dos municípios, sendo esta parceria fundamental para a execução do projeto.

Os dados foram coletados mediante entrevista semi-estruturada junto aos agricultores familiares em seus respectivos locais de trabalho, contendo questões abertas e fechadas (Seixas, 2005), onde o informante abordou livremente o tema proposto (Deslandes \& al., 1994; Freudenberger, 1994). Considerou-se como unidade amostral o estabelecimento agropecuário (unidade de produção familiar). Ao todo foram realizadas 68 entrevistas representando, no mínimo, 10 entrevistas em cada município.

A listagem das plantas conhecidas pelos informantes foi obtida a partir da técnica de listagem livre (Bernard, 1995), presente na segunda parte do questionário. Durante essas entrevistas também foi questionado sobre a utilidade das plantas citadas.

\section{Análise dos Dados}

Quanto aos usos, as espécies foram classificadas como medicinal, ornamental, madeireiro ou alimentício, sendo que cada espécie pode ser classificada em mais de uma categoria.

$\mathrm{Na}$ interpretação dos dados, foram usadas estratégias qualitativas e quantitativas. As informações usadas na análise qualitativa consistiram das entrevistas realizadas e do referencial teórico pesquisado, os quais foram codificados e sistematizados.

As curvas de rarefação e suas respectivas curvas de intervalo de confiança auxiliaram na comparação da riqueza de espécies citadas em cada formação florestal, associada ao índice de Sobs. As curvas de rarefação adaptadas para uso em estudos etnobotânicos consideram cada informante uma unidade amostral (Peroni \& al., 2008). As curvas de acumulação de espécies (curvas de rarefação, segundo Gotelli \& Colwell, 2001) foram obtidas com o uso do programa EstimateS 8.0 (Colwell, 2006), assim como os respectivos intervalos de confiança a $95 \%$ de probabilidade, utilizando as fórmulas analíticas apresentadas em Colwell \& al. (2004).

Adicionalmente, foram estimados os índices de Valor de Diversidade do Informante (VDI) no que se refere ao número de espécies conhecidas, calculando-seo número de espécies citadas por um dado informante, dividido pelo número total de informantes (adaptado de Byg \& Baslev, 2001). Este índice colaborou para o entendimento de como o conhecimento de espécies está distribuído entre informantes dos municípios de mesma formação florestal, mas com histórico de colonização distintos. $\mathrm{O}$ emprego deste índice apresentou-se adequado para a caracterização das amostras, mesmo aquelas de diferentes tamanhos, pois este não é sensível à amostragem (Hoffman \& Gallaher, 2007).

Foi usado teste de Kruskal-Wallis a 5\% probabilidade para verificar diferenças significativas relacionadas ao número de espécies conhecidas entre os informantes, agrupados de acordo com a cidade de residência dentro de cada formação florestal, idade, tamanho da propriedade ou percentagem da propriedade com mata.

A identificação taxonômica das espécies citadas foi realizada a campo quando inequívoca. Nos casos de dúvida foi procedida a coleta de exsicatas compostas de partes vegetativas e/ou reprodutivas, depositadas no acervo do Núcleo de Pesquisas em Florestas Tropicais (NPFT - UFSC). Nesse caso, a identificação foi feita com auxílio de

${ }^{1}$ Projeto de desenvolvimento agrícola visando recuperação ambiental e de apoio ao pequeno produtor rural. 
bibliografia especializada (diversos volumes da Flora Ilustrada Catarinense), e confirmadas através de consultas a especialistas.

\section{Resultados e Discussão}

\section{Caracterização das propriedades}

Em todas as regiões a característica básica foi de pequenos proprietários rurais, com área média das propriedades de 30 hectares (ha) (Tabela 1), apresentando, no entanto, um perfil distinto. Em Anchieta e Concórdia a ocupação do território foi iniciada basicamente após a década de 1940, onde alguns dos informantes foram os próprios colonizadores com média de idade de 60 anos, originários em sua maioria do Estado do Rio Grande do Sul. Em Caçador e na região de Três Barras a média de idade foi de 48 anos, formado basicamente por agricultores que são a primeira ou segunda geração nascida na região após o processo de colonização (década de 1920). Em São Pedro de Alcântara, alguns agricultores entrevistados são descendentes do primeiro processo de colonização Alemã de Santa Catarina (1829), mas a maior parte $(67 \%)$ é originária de municípios próximos a São Pedro de Alcântara, resultado da impossibilidade de maior divisão da propriedade rural na qual seus pais trabalhavam. Por sua vez, em Garuva a maior parte dos entrevistados está na região há pouco tempo, em média 30 anos, motivados pela expansão das culturas da banana e do arroz na região.

O histórico de ocupação das regiões, exceto Garuva, tem origem semelhante, sendo os agricultores incentivados pela demanda de terras oferecidas pelas empresas colonizadoras. Segundo Nodari (1999), a partir do fim da Guerra do Contestado (1915), o governo de Santa Catarina passou a tomar medidas para a organização político-administrativa da região oeste. Para garantir a posse definitiva das terras o governo buscou desencadear um processo de colonização e povoação da região através de empresas colonizadoras que recebiam do Estado terras devolutas ${ }^{1}$ em troca da construção de estradas e assentamentos de migrantes e imigrantes na região.

O uso atual do solo está representado na Tabela 1. Considerando o uso agropecuário, destacaram-se as lavouras em quase todas as regiões, sendo representadas principalmente pelo milho e feijão na região de Anchieta e Concórdia, tomate em Caçador, soja em Três Barras, cana-de-açúcar e mandioca em São Pedro de Alcântara e, banana e arroz em Garuva. Na região de São Pedro de Alcântara, as pastagens possuem uma área superior as lavouras, associada principalmente à atividade de pecuária de corte, diferente das áreas de pastagens nos municípios de Anchieta e Concórdia, que estão associadas principalmente à atividade de pecuária leiteira. Segundo Zuchiwschi (2008) no município de Anchieta, $81 \%$ dos agricultores se dedicam a essa atividade, e a perspectiva futura é de incremento da área destinada a este uso da terra, especialmente em detrimento das áreas de lavouras.

Com relação às áreas de remanescentes florestais (Mata e Capoeira), apesar de representarem mais de $20 \%$ da área total das propriedades, apenas 13\% (9) das propriedades têm averbada a área de reserva legal (RL), conforme preconiza o Código Florestal brasileiro (Brasil, 1965).

$\mathrm{O}$ alto percentual da cobertura vegetal denominada Mata na região de Três Barras está associado principalmente às áreas chamadas de caívas. As caívas ou "terras de criá" são as áreas de cobertura florestal onde os animais domésticos (porcos, cavalos, gado bovino e outros) são criados soltos, alimentandose das frutas e plantas disponíveis no subbosque destas formações. Essas áreas são remanescentes dos sistemas de produção conhecidos como faxinais (Chang, 1988), tema abordado com detalhes mais adiante. Do ponto de vista de conservação, o sistema serve como forma de manutenção da paisagem florestal, apesar do impacto sobre a regeneração natural promovido pelo pastejo.

De forma geral, os dados de uso da terra são

${ }^{1}$ Terras devolutas são todas aquelas que não estavam sob o domínio privado ou que não estivessem destinadas a um fim público, e que com a Independência foram devolvidas ao Estado brasileiro, criado em 1824 (Ramos, 2006). 
coerentes com médias relatadas pela Secretaria de Estado da Agricultura e Desenvolvimento Rural para cada município, através do Levantamento Agropecuário Catarinense LAC 2002-2003 (Icepa, 2005). A exceção está nas estimativas das áreas florestais, para as quais o LAC aponta áreas de florestas secundárias (capoeiras) significativamente menores em todos municípios: Anchieta $(6,9 \%)$, Caçador $(7,1 \%)$, Concórdia $(9,1 \%)$, Garuva (2,7\%), São Pedro de Alcântara (7\%) e Três Barras 1,7\%. Em contrapartida, as áreas consideradas de Mata foram superiores em quatro municípios: Anchieta (7,8\%), Caçador (29,9\%), Concórdia (14,7\%), Garuva, (27,0\%) e São Pedro de Alcântara (37\%). Possivelmente estas diferenças se devem ao fato de que muitas áreas de formações florestais secundárias foram consideradas no LAC como áreas de Mata, uma vez que, o levantamento considerou como capoeira apenas "áreas com até 6 anos, ocupadas com mato ralo ou capoeirão, utilizada ou não para o pastejo do gado na data de referência" , enquanto que a Mata natural " $E$ a área coberta por matas naturais (não plantadas), inclusive as destinadas para reserva mínima ou para proteção ambiental ou ainda para fins cientificos e biológicos, independente de sofrerem ação extrativista" (Icepa, 2005).

\section{Conhecimento e uso dos recursos florestais}

Ao todo foram citadas pelos agricultores 160 espécies com importância de uso no passado ou atual, nos seis municípios estudados. Foram citadas um número similar de espécies nas diferentes regiões (FED 71, FOM 73, e FOD 79), distribuídas nas categorias de uso madeireiro (85), medicinal (69), alimentício (28) e ornamental (18) (Tabela 2). A curva de rarefação para citações das espécies nas entrevistas (Fig. 2) aponta uma tendência para a estabilidade nas três formações florestais, demonstrando que a amostra utilizada foi suficiente para representar as principais espécies citadas pelos entrevistados.

O número médio de citação para espécies presentes em três formações florestais de Santa Catarina nas diferentes categorias estruturadas (idade, município, tamanho das propriedades, e área de mata na propriedade), acrescido do valor de diversidade do informante (VDI), apresentou grande homogeneidade entre os grupos, não existindo diferença estatisticamente significativa para a maioria (Tabela 3). Houve apenas diferença em relação ao município e ao tamanho da propriedade na Floresta Estacional Decidual.

O número de espécies citadas reflete a forte interação que os agricultores estabeleceram com o ambiente onde estão inseridos, como consequência de suas observações, experimentações e adaptações frente às necessidades do dia-a-dia. A importância e o uso dos recursos florestais nativos nos estabelecimentos rurais no Estado faz parte da própria história de ocupação da região, influenciando e sendo influenciada pelas relações sociais, culturais e econômicas ao longo de sua história, onde algumas particularidades de cada região podem ser destacadas.

Por sua similaridade florística, os municípios foram agrupados conforme a formação florestal de ocorrência:

Floresta Estacional Decidual. Região onde estão situados os municípios de Anchieta e Concórdia.Apesar dos dois municípios estarem situados em região de mesma tipologia florestal, e com histórico de ocupação semelhante, a relação com os recursos florestais apresentouse de forma distinta. Em Anchieta, o início do período de colonização (1940) foi marcado por uma intensa exploração de recursos madeireiros, baseada em um grupo de espécies com características decíduas e que formavam o dossel característico da FED. Nesse grupo de plantas, se destacam espécies como a "grápia" (Apuleia leiocarpa), "cedro" (Cedrela fissilis), "louro" (Cordia trichotoma), pau-marfim (Balfourodendron riedelianum), "canafístula" (Peltophorum dubium), "angico-vermelho" (Parapiptadenia rigida) e a "cabreúva" (Myrocarpus frondosus). O uso dos recursos teve como objetivos fornecer matéria-prima para as construções e equipamentos, abertura de áreas para as atividades agropecuárias e geração de renda nos primeiros anos de atividades na região, através da venda da madeira.

Já na região de Concórdia, o uso de recursos 
A. Siminski et al., Recursos Florestais Nativos e a Agricultura Familiar em Santa Catarina, Brasil


Fig. 2. Curvas de rarefação de espécies citadas por informantes residentes nas formações florestais. A: Floresta Estacional Decidual (27). B: Floresta Ombrófila Densa (20). C: Floresta Ombrófila Mista (21).* Entre parênteses número de informantes por formação florestal. 
Tabela 1. Uso atual da terra em estabelecimentos agrícolas nos seis municípios do Estado de Santa Catarina.

\begin{tabular}{|c|c|c|c|c|c|c|c|}
\hline \multirow{3}{*}{ Local de Estudo } & \multirow{3}{*}{$\begin{array}{c}\text { Tamanho médio } \\
\text { da propriedade } \\
\text { (ha) }\end{array}$} & \multicolumn{6}{|c|}{ Uso da terra $(\%)$} \\
\hline & & \multicolumn{3}{|c|}{ Agropecuário } & \multirow{2}{*}{ Outros } & \multicolumn{2}{|c|}{ Florestal } \\
\hline & & Pastagem & Lavouras & Reflorestamento & & Mata & Capoeiras \\
\hline $\begin{array}{l}\text { Anchieta } \\
\text { (n14) }\end{array}$ & 12,3 & 30 & 37 & 3 & 5 & 5 & 20 \\
\hline $\begin{array}{l}\text { Caçador } \\
\text { (n11) }\end{array}$ & 19,8 & 13 & 35 & 10 & 5 & 7 & 30 \\
\hline $\begin{array}{l}\text { Concórdia } \\
\text { (n13) }\end{array}$ & 45,1 & 25 & 35 & 6 & 10 & 10 & 14 \\
\hline $\begin{array}{c}\text { Garuva } \\
\text { (n10) }\end{array}$ & 31,1 & 19 & 43 & 8 & 2 & 16 & 12 \\
\hline $\begin{array}{l}\text { São Pedro de } \\
\text { Alcântara } \\
\text { (n10) }\end{array}$ & 30,3 & 25 & 14 & 3 & 2 & 13 & 43 \\
\hline $\begin{array}{l}\text { Três Barras } \\
\text { (n10) }\end{array}$ & 41,6 & 19 & 40 & 7 & 4 & 25 & 5 \\
\hline Média & 30,0 & 21,8 & 34,0 & 6,2 & 4,7 & 12,7 & 20,6 \\
\hline
\end{tabular}

madeireiros esteve baseado, em um primeiro momento, na exploração do "cedro" (Cedrela fissilis). A madeira era levada até o município de São Borja-RS utilizando o rio Uruguai na época "das cheias", e de lá para o Uruguai e a Argentina onde eram comercializadas. Para transportar as toras utilizava-se o sistema de balsas, que consistia em amarrar de cento e cinquenta a duzentas toras de madeira umas às outras. Em torno desta atividade, estavam muitos trabalhadores como os peões, que derrubavam a mata e levavam as toras, utilizando juntas de boi, até o rio Uruguai, e os balseiros, que se ocupavam no transporte das madeiras. Normalmente, os agricultores vendiam a madeira "em pé", ou seja, ainda na floresta.

Apenas no final da década de 1940, já com escassez do cedro, começaram a ser explorados outros recursos madeireiros como a "grápia" (Apuleia leiocarpa), "louro-pardo" (Cordia trichotoma), "pau-marfim" (Balfourodendron riedelianum), "canafístula" (Peltophorum dubium) ea "cabreúva"(Myrocarpus frondosus). Entre as décadas de 1940 e 1950, também houve um momento de intensa exploração da "canelasassafrás" (Ocotea odorifera), inclusive com a operação de duas fábricas de extração de óleo em uma das comunidades pesquisada (Sede Brum). Esta característica fez com que os valores obtidos para o VDI quanto ao número de espécies citadas fossem estatisticamente diferentes $(\mathrm{p}<.001)$ entre os dois municípios (Tabela 3).

Quando investigados os outros usos de recursos florestais, destacam-se nesta região as espécies alimentícias como a "sete-capotes" (Campomanesia guazumifolia), "uvaia" (Eugenia pyriformis), "jabuticaba" (Plinia trunciflora), "cereja" (Eugenia involucrata), "guabiroba" (Campomanesia xanthocarpa), "araucária" (Araucaria angustifolia), e a "pitanga" (Eugenia uniflora). As plantas medicinais com maior número de citações de uso foram a "erva-mate" (Ilex paraguariensis), "guaçatonga" (Casearia sylvestris), o "cincho" (Sorocea bonplandii) e a "pata-de-vaca" (Bauhinia forficata) (Tabela 2).

Floresta Ombrófila Mista. Neste trabalho esta região foi representada pelos municípios de Caçador e Três Barras, onde o processo exploratório de espécies madeireiras foi concentrado em duas espécies, a "araucária" e a "imbuía" (Ocotea porosa). Muitas vezes, a exploração deste recurso esteve associada ao processo de colonização, onde a detentora das árvores era a própria empresa que vendia os terrenos aos colonizadores, apesar das árvores ainda não terem sido retiradas.

No caso específico da região de Três Barras, ainda é muito forte entre os agricultores a associação entre o processo de exploração de 
A. Siminski et al., Recursos Florestais Nativos e a Agricultura Familiar em Santa Catarina, Brasil

Tabela 2. Espécies nativas citadas por 68 agricultores familiares em Santa Catarina, suas famílias botânicas, denominações locais, número de citações por formação florestal e usos. FED: Floresta Estacional Decidual, FOD: Floresta Ombrófila

Densa, FOM: Floresta Ombrófila Mista. Me: Medicinal, Md: Madeireiro, Alim: Alimentício e Orn: Ornamental

\begin{tabular}{|c|c|c|c|c|c|c|}
\hline \multirow{2}{*}{ Família botânica } & \multirow{2}{*}{ Nome científico/autor } & \multirow{2}{*}{ Etnoespécie } & \multicolumn{3}{|c|}{ Citações } & \multirow[b]{2}{*}{ Usos } \\
\hline & & & FED & FOM & FOD & \\
\hline AMARANTHACEAE & $\begin{array}{l}\text { Pfaffia glomerata (Spreng.) } \\
\text { Pedersen }\end{array}$ & ginsen & & & 4 & $\mathrm{Me}$ \\
\hline ANACARDIACEAE & $\begin{array}{l}\text { Schinus terebinthifolius } \\
\text { Raddi }\end{array}$ & aroeira & 6 & 8 & & $\mathrm{Me} / \mathrm{Md}$ \\
\hline \multirow[t]{6}{*}{ ANNONACEAE } & Annona cacans Warm. & pinha & 8 & & & Alim \\
\hline & Annona glabra L. & pinha & & & 8 & Me/Alim \\
\hline & Annona salicifolia Schltdl. & ariticum & & 7 & & Alim \\
\hline & $\begin{array}{l}\text { Annona sericea (R.E.Fries) } \\
\text { R.E.Fries. }\end{array}$ & ariticum & & & 6 & Me/Alim \\
\hline & Annona sylvatica A.St.-Hil. & cortica & & & 4 & $\mathrm{Md}$ \\
\hline & $\begin{array}{l}\text { Xylopia brasiliensis } \\
\text { Sprengel }\end{array}$ & pindaíva & & & 2 & $\mathrm{Md}$ \\
\hline APOCYNACEAE & $\begin{array}{l}\text { Aspidosperma polyneuron } \\
\text { Muell. Arg. }\end{array}$ & peroba & & & 6 & $\mathrm{Md}$ \\
\hline \multirow[t]{2}{*}{ AQUIFOLIACEAE } & $\begin{array}{l}\text { Ilex paraguariensis A. St.- } \\
\text { Hill. }\end{array}$ & erva-mate & 20 & 20 & & Me/Alim \\
\hline & $\begin{array}{l}\text { Ilex theezans Mart. ex } \\
\text { Reissek }\end{array}$ & caúna & 2 & 6 & & Me/Alim \\
\hline ARACEAE & $\begin{array}{l}\text { Philodendron corcovadense } \\
\text { Kunth }\end{array}$ & cipó-imbe & & & 12 & Orn \\
\hline ARALIACEAE & $\begin{array}{l}\text { Schefflera morototoni } \\
\text { (Aubl.) Maguire, Stey. \& } \\
\text { Frod }\end{array}$ & mandioqueiro & 3 & & 8 & $\mathrm{Md}$ \\
\hline ARAUCARIACEAE & $\begin{array}{l}\text { Araucaria angustifolia } \\
\text { (Bertol.) Kuntze }\end{array}$ & pinheiro & 11 & 21 & & Alim/Md \\
\hline \multirow[t]{5}{*}{ ARECACEAE } & Euterpe edulis Mart. & palmito & & & 20 & $\begin{array}{l}\text { Me/Orn/ } \\
\text { Md/Alim }\end{array}$ \\
\hline & Geonoma gamiova Barb. & guaricana & & & 10 & Orn \\
\hline & $\begin{array}{l}\text { Syagrus romanzoffiana } \\
\text { (Cham.) Glassman }\end{array}$ & coqueiro & 7 & 9 & 4 & Me/Alim \\
\hline & $\begin{array}{l}\text { Bactris lindmaniana Drude } \\
\text { ex Lindman }\end{array}$ & tucun & & & 6 & Orn \\
\hline & Butia capitata Mart. Becc. & butiá & & & 8 & Alim \\
\hline ARISTOLOCHIACEAE & $\begin{array}{l}\text { Aristolochia triangularis } \\
\text { Cham. Et Schl. }\end{array}$ & mil-homens & 8 & 3 & 4 & $\mathrm{Me}$ \\
\hline \multirow[t]{5}{*}{ ASTERACEAE } & $\begin{array}{l}\text { Achyrocline satureioides } \\
\text { (Lam.) DC. }\end{array}$ & macela & & 9 & & Me/Orn \\
\hline & $\begin{array}{l}\text { Baccharis articulata (Lam.) } \\
\text { Pers. }\end{array}$ & carqueja-doce & & & 2 & $\mathrm{Me}$ \\
\hline & $\begin{array}{l}\text { Baccharis dracunculifolia } \\
\text { DC. }\end{array}$ & vassoura & & 2 & & $\mathrm{Me}$ \\
\hline & $\begin{array}{l}\text { Baccharis trimera (Less.) } \\
\text { DC. }\end{array}$ & carqueja & & 12 & & $\mathrm{Me}$ \\
\hline & $\begin{array}{l}\text { Butia eriospatha (Mart. ex. } \\
\text { Drude) Becc. }\end{array}$ & butiá & & 12 & & Ali \\
\hline
\end{tabular}




\begin{tabular}{|c|c|c|c|c|c|c|}
\hline \multirow{2}{*}{ Família botânica } & \multirow{2}{*}{ Nome científico/autor } & \multirow{2}{*}{ Etnoespécie } & \multicolumn{3}{|c|}{ Citações } & \multirow{2}{*}{ Usos } \\
\hline & & & FED & FOM & FOD & \\
\hline & Piptocarpha angustifolia & vassorão- & & 7 & & $\mathrm{Md}$ \\
\hline & Dusén ex Malme & branco & & & & \\
\hline & Senecio brasiliensis Less. & flor-das-almas & & 3 & & $\mathrm{Me}$ \\
\hline & Vernonia discolor (Spreng.) & vassorão-preto & & 2 & & Md \\
\hline & Less. & & & & & \\
\hline & Mikania glomerata Spreng. & guaco & & & 4 & $\mathrm{Me}$ \\
\hline & Mikania involucrata Hook & guaco & & 7 & & $\mathrm{Me}$ \\
\hline & \& Arn. & & & & & \\
\hline & $\begin{array}{l}\text { Mikania laevigata Sch. Bip. } \\
\text { ex Baker }\end{array}$ & guaco & & & 4 & $\mathrm{Me}$ \\
\hline \multirow[t]{3}{*}{ BIGNONEACEAE } & Pyrostegia venusta Presl. & cipó-são-joão & 1 & 3 & & Me/Orn \\
\hline & $\begin{array}{l}\text { Tabebuia chrysotricha } \\
\text { (Mart. ex DC.) Standl. }\end{array}$ & ipê-amarelo & & & 4 & Md \\
\hline & $\begin{array}{l}\text { Tabebuia heptaphylla } \\
\text { (Vell.) }\end{array}$ & ipê-roxo & 8 & 4 & & $\mathrm{Me} / \mathrm{Md}$ \\
\hline \multirow[t]{7}{*}{ BORAGINACEAE } & Cordia americana (L.) & guajuvira & 10 & & & Md \\
\hline & Gotlschling \& J.E. Mill. & & & & & \\
\hline & Cordia curassavica (Jacq.) & baleeira & & & 8 & $\mathrm{Me}$ \\
\hline & Roem. \& Schult. & & & & & \\
\hline & Cordia ecalyculata Vell. & louro & 2 & & & $\mathrm{Md}$ \\
\hline & Cordia trichotoma (Vell.) & louro-pardo & 16 & 1 & 4 & $\mathrm{Md}$ \\
\hline & Arráb. ex Steud. & & & & & \\
\hline \multirow[t]{4}{*}{ BROMELIACEAE } & Ananas bracteatus (Lindl.) & caraguatá & & & 2 & Alim \\
\hline & Schult. \& Schult. f. & & & & & \\
\hline & Bromelia antiacantha & caraguatá & & 15 & & $\mathrm{Me}$ \\
\hline & Bertol. & & & & & \\
\hline CANELACEAE & $\begin{array}{l}\text { Capsicodendron dinisii } \\
\text { Schwacke }\end{array}$ & pimenteira & & 11 & & $\mathrm{Me} / \mathrm{Md}$ \\
\hline \multirow[t]{3}{*}{ CANNABACEAE } & $\begin{array}{l}\text { Celtis iguanaea (Jacq.) } \\
\text { Sarg. }\end{array}$ & grão-de-galo & 2 & & & Me/Alim \\
\hline & Trema micrantha (L.) & grandiúva & 2 & & & Md \\
\hline & Blume & & & & & \\
\hline CAPRIFOLIACEAE & $\begin{array}{l}\text { Sambucus australis Cham. } \\
\text { \& Schltdl. }\end{array}$ & sabugueiro & 1 & & & $\mathrm{Me}$ \\
\hline CARICACEAE & $\begin{array}{l}\text { Carica quercifolia (A. St.- } \\
\text { Hil.) Hieron. }\end{array}$ & mamoazinho & 2 & & & Alim \\
\hline CECROPIACEAE & $\begin{array}{l}\text { Cecropia glaziouii } \\
\text { Snethlage }\end{array}$ & embaúba & & & 4 & Me/Orn \\
\hline CELASTRACEAE & $\begin{array}{l}\text { Maytenus muelleri } \\
\text { Schwacke }\end{array}$ & $\begin{array}{l}\text { espinheira- } \\
\text { santa }\end{array}$ & & 18 & & $\begin{array}{l}\text { continua.. } \\
\text { Me }\end{array}$ \\
\hline CHLORANTACEAE & $\begin{array}{l}\text { Hedyosmum brasiliensis } \\
\text { Mart. }\end{array}$ & cidrão & & & 6 & $\mathrm{Me}$ \\
\hline CLETHRACEAE & $\begin{array}{l}\text { Clethra scabra (Meissan.) } \\
\text { Sleum }\end{array}$ & carne-de-vaca & & 5 & 4 & Md \\
\hline \multirow[t]{2}{*}{ CLUSIACEAE } & $\begin{array}{l}\text { Calophyllum brasiliense } \\
\text { Cambess. }\end{array}$ & guanandi & & & 12 & $\mathrm{Md}$ \\
\hline & $\begin{array}{l}\text { Garcinia gardneriana } \\
\text { (Planch. \& Triana) Zappi }\end{array}$ & bacupari & & & 12 & Alim/Md \\
\hline
\end{tabular}


A. Siminski et al., Recursos Florestais Nativos e a Agricultura Familiar em Santa Catarina, Brasil

\begin{tabular}{|c|c|c|c|c|c|c|}
\hline \multirow{2}{*}{ Família botânica } & \multirow{2}{*}{ Nome científico/autor } & \multirow{2}{*}{ Etnoespécie } & \multicolumn{3}{|c|}{ Citações } & \multirow{2}{*}{ Usos } \\
\hline & & & FED & FOM & FOD & \\
\hline DICKSONIACEAE & Dicksonia sellowiana Hook & xaxin & & 12 & & $\mathrm{Me} / \mathrm{Orn}$ \\
\hline ELAEOCARPACEAE & $\begin{array}{l}\text { Sloanea guianensis (Aubl.) } \\
\text { Benth }\end{array}$ & $\begin{array}{l}\text { laranjeira-do- } \\
\text { mato }\end{array}$ & & & 1 & $\mathrm{Md}$ \\
\hline EQUISETACEAE & Equisetum giganteum L. & cavalinha & & 2 & & $\mathrm{Me}$ \\
\hline ERYTHROXYLACEAE & $\begin{array}{l}\text { Erytroxylum cuneifolium } \\
\text { (Mart.) O.E.Schulz }\end{array}$ & cocão & & & 2 & $\mathrm{Me}$ \\
\hline \multirow[t]{6}{*}{ EUPHORBIACEAE } & $\begin{array}{l}\text { Alchornea triplinervia } \\
\text { (Spreng.) Müll. Arg. }\end{array}$ & tanheiro & & & 8 & $\mathrm{Md}$ \\
\hline & Croton celtidifolius Baill & $\begin{array}{l}\text { sangue-de- } \\
\text { dragão }\end{array}$ & & & 2 & $\mathrm{Me}$ \\
\hline & $\begin{array}{l}\text { Hyeronima alchorneoides } \\
\text { Fr Allem }\end{array}$ & licurana & & & 14 & $\mathrm{Md}$ \\
\hline & Pera glabrata (Schott) Baill & seca-ligeiro & & & 1 & Md \\
\hline & Sapium glandulosum (L.) & leiteiro & & 1 & & Orn \\
\hline & $\begin{array}{l}\text { Morong } \\
\text { Sebastiania commersoniana } \\
\text { (Baillon) L.B. Smith \& } \\
\text { R.J.Downs }\end{array}$ & branquilho & & 5 & & $\mathrm{Md}$ \\
\hline \multirow[t]{17}{*}{ FABACEAE } & Apuleia leiocarpa (Vog.) & grápia & 20 & & & Md \\
\hline & Macbr. & & & & & \\
\hline & Ateleia glazioviana Baill & timbó & 15 & & & Md \\
\hline & Bauhinia forficata Link. & pata-de-vaca & 10 & & 6 & $\mathrm{Me}$ \\
\hline & Calliandra tweediei Benth. & cabelo-de-anjo & 2 & & & $\mathrm{Md} / \mathrm{Orn}$ \\
\hline & Colubrina glandulosa Perk & sobraji & 2 & & & Md \\
\hline & $\begin{array}{l}\text { Copaifera trapezifolia } \\
\text { Hayne }\end{array}$ & pau-óleo & & & 6 & $\mathrm{Me} / \mathrm{Md}$ \\
\hline & Dalbergia frutescens Britton & canela-do-brejo & 13 & & & $\mathrm{Md}$ \\
\hline & Erythrina falcata Benth. & corticeira & 7 & & & $\mathrm{Md} / \mathrm{Orn}$ \\
\hline & $\begin{array}{l}\text { Holocalix balanseae } \\
\text { Micheli }\end{array}$ & alecrim & 1 & & & Md \\
\hline & $\begin{array}{l}\text { Machaerium stipitatum } \\
\text { (DC.) Vog. }\end{array}$ & farinha-seca & 6 & & & $\mathrm{Md}$ \\
\hline & Mimosa scabrella Benth & bracatinga & 3 & 19 & & $\mathrm{Md}$ \\
\hline & $\begin{array}{l}\text { Myrocarpus frondosus } \\
\text { Allem. }\end{array}$ & cabruva & 10 & & & Md \\
\hline & $\begin{array}{l}\text { Parapiptadenia rigida } \\
\text { (Benth.) Brenan }\end{array}$ & angico & 20 & & & $\mathrm{Md}$ \\
\hline & $\begin{array}{l}\text { Peltophorum dubium } \\
\text { (Spreng.) Taub. }\end{array}$ & canafístula & 2 & & & $\mathrm{Md}$ \\
\hline & $\begin{array}{l}\text { Schizolobium parahyba } \\
\text { (Vell.) Blake }\end{array}$ & guarapuvú & & & 6 & $\mathrm{Md}$ \\
\hline & Zollernia ilicifolia Vog. & $\begin{array}{l}\text { espinheira- } \\
\text { santa }\end{array}$ & & & 8 & $\mathrm{Me}$ \\
\hline HELICONIACEAE & $\begin{array}{l}\text { Heliconia velloziana } \mathrm{L} \text {. } \\
\text { Emygd. }\end{array}$ & heliconia & & & 2 & Orn \\
\hline \multirow[t]{2}{*}{ LAMIACEA } & Cunila microcephala Benth. & poejo & & & 4 & $\mathrm{Me}$ \\
\hline & Ocimum selloi Benth. & gervão & & & 1 & $\mathrm{Me}$ \\
\hline LAURACEAE & $\begin{array}{l}\text { Cinnamomum amoenum } \\
\text { (Nees) Kosterm. }\end{array}$ & canela-alho & & 4 & & Md \\
\hline
\end{tabular}




\begin{tabular}{|c|c|c|c|c|c|c|}
\hline \multirow{2}{*}{ Família botânica } & \multirow{2}{*}{ Nome científico/autor } & \multirow{2}{*}{ Etnoespécie } & \multicolumn{3}{|c|}{ Citações } & \multirow{2}{*}{ Usos } \\
\hline & & & FED & FOM & FOD & \\
\hline & $\begin{array}{l}\text { Nectandra megapotamica } \\
\text { (Spreng.) Mez }\end{array}$ & canela-preta & 7 & & & $\mathrm{Md}$ \\
\hline & Ocotea catharinensis $\mathrm{Mez}$ & canela-preta & & & 9 & $\mathrm{Md}$ \\
\hline & $\begin{array}{l}\text { Ocotea diospyrifolia } \\
\text { (Meisn.) Mez }\end{array}$ & canela-loura & 3 & & & $\mathrm{Md}$ \\
\hline & Ocotea odorifera (Vellozo) & sassafrás & 6 & & 4 & $\mathrm{Me} / \mathrm{Md}$ \\
\hline & Rohwer & & & & & \\
\hline & $\begin{array}{l}\text { Ocotea porosa (Nees \& C. } \\
\text { Mart.) Barroso }\end{array}$ & imbuia & & 20 & & Md \\
\hline & $\begin{array}{l}\text { Ocotea puberula (Rich.) } \\
\text { Nees }\end{array}$ & canela-pinha & 3 & 8 & & $\mathrm{Md}$ \\
\hline LAXMANNIACEAE & $\begin{array}{l}\text { Cordyline spectabilis Kunth } \\
\text { \& Bouché }\end{array}$ & varana & & 4 & & Orn \\
\hline LOGANIACEAE & Strychnos brasiliensis Mart. & espora-de-galo & 2 & & 1 & $\mathrm{Me}$ \\
\hline LYTHRACEAE & $\begin{array}{l}\text { Cuphea carthagenensis } \\
\text { (Jacq.) J.F.Macbr. }\end{array}$ & sete-sangria & & 2 & 4 & $\mathrm{Me}$ \\
\hline MAGNOLIACEAE & Talauma ovata A.St.-Hil. & baguaçú & & & 2 & Md \\
\hline MALVACEAE & Luehea divaricata Mart. & açoita & 12 & & & $\mathrm{Me} / \mathrm{Md}$ \\
\hline \multirow[t]{3}{*}{ MELASTOMATACEAE } & $\begin{array}{l}\text { Miconia cinnamomifolia } \\
\text { (DC) Naudin }\end{array}$ & $\begin{array}{l}\text { jacatirão-de- } \\
\text { copada }\end{array}$ & & & 16 & $\mathrm{Md}$ \\
\hline & Tibouchina pulchra Cogn. & jacatirão & & & 13 & Md \\
\hline & $\begin{array}{l}\text { Tibouchina sellowiana } \\
\text { (Cham.) Cogn. }\end{array}$ & quaresmeira & & & 6 & Md/Orn \\
\hline \multirow[t]{5}{*}{ MELIACEAE } & Cabralea canjerana (Vell) & canjerana & 8 & 7 & 4 & Md \\
\hline & Mart. & & & & & \\
\hline & Cedrela fissilis Vell. & cedro & 20 & 10 & 11 & $\mathrm{Md}$ \\
\hline & Trichilia catigua A. Juss. & catigua & 2 & 6 & & $\mathrm{Me}$ \\
\hline & Trichilia $\mathrm{sp}$ & catigua & & & 2 & $\begin{array}{c}\text { Me } \\
\text { continua.. }\end{array}$ \\
\hline \multirow[t]{3}{*}{ MORACEAE } & Ficus organensis Miq. & figueira & & & 8 & $\begin{array}{l}\mathrm{Me} / \mathrm{Md} / \\
\text { Alim }\end{array}$ \\
\hline & $\begin{array}{l}\text { Maclura tinctoria (L.) D. } \\
\text { Don ex Steudel. }\end{array}$ & tajuva & 6 & & & $\mathrm{Md}$ \\
\hline & $\begin{array}{l}\text { Sorocea bonplandii (Bail.) } \\
\text { Burg. Lanj \& Boer }\end{array}$ & cincho & 13 & & & $\mathrm{Me}$ \\
\hline \multirow[t]{4}{*}{ MYRISTICACEAE } & Virola bicuhyba Schott & bicuíba & & & 8 & $\mathrm{Md}$ \\
\hline & Myrsine coriacea (Swartz) & capororoca & & & 10 & $\mathrm{Md}$ \\
\hline & $\begin{array}{l}\text { R. Brown ex Roemer \& } \\
\text { Schultz }\end{array}$ & & & & & \\
\hline & $\begin{array}{l}\text { Myrsine umbellata Mat ex. } \\
\text { DC. }\end{array}$ & capororocão & & 2 & & $\mathrm{Md}$ \\
\hline \multirow[t]{5}{*}{ MYRTACEAE } & Acca sellowiana Berg. & goiaba-do-mato & & 10 & & Alim/Md \\
\hline & $\begin{array}{l}\text { Campomanesia } \\
\text { guazumifolia (Cambess.) O. } \\
\text { Berg. }\end{array}$ & sete-capote & 16 & & & $\begin{array}{l}\text { Me/Alim/ } \\
\text { Md }\end{array}$ \\
\hline & $\begin{array}{l}\text { Campomanesia xanthocarpa } \\
\text { O.Berg. }\end{array}$ & guabiroba & 12 & & 16 & Alim \\
\hline & Eugenia involucrata DC. & cereja & 14 & 3 & & Alim \\
\hline & Eugenia pyriformis Camb. & uvaia & 16 & 15 & & Alim \\
\hline
\end{tabular}


A. Siminski et al., Recursos Florestais Nativos e a Agricultura Familiar em Santa Catarina, Brasil

\begin{tabular}{|c|c|c|c|c|c|c|}
\hline \multirow{2}{*}{ Família botânica } & \multirow{2}{*}{ Nome científico/autor } & \multirow{2}{*}{ Etnoespécie } & \multicolumn{3}{|c|}{ Citações } & \multirow{2}{*}{ Usos } \\
\hline & & & FED & FOM & FOD & \\
\hline & Mosiera prismatica (D). & cerninho & & 7 & & $\mathrm{Md}$ \\
\hline & Legrand) Landrum & & & & & \\
\hline & Myrcia rostrata DC. & guamirim & & & 2 & Md \\
\hline & $\begin{array}{l}\text { Myrcianthes pungens } \\
\text { (O.Berg) Legr. }\end{array}$ & guabiju & 9 & & & Alim/Md \\
\hline & Myrciaria tenella (DC.) & cambuí & & 4 & & Md \\
\hline & O.Berg & & & & & \\
\hline & Plinia trunciflora (DC) Berg & jabuticaba & 15 & 2 & & Alim \\
\hline & Psidium cattleyanum Sabine & araçá & 2 & 10 & 12 & Alim \\
\hline & $\begin{array}{l}\text { Blepharocalyx salicifolius } \\
\text { (Kunth) O.Berg }\end{array}$ & murta & & 1 & & $\mathrm{Me} / \mathrm{Md}$ \\
\hline \multirow[t]{2}{*}{ NYCTAGINACEAE } & Guapira opposita (Vell.) & maria-mole & & & 4 & $\mathrm{Md}$ \\
\hline & Reitz & & & & & \\
\hline OQUIDACEAE & Cattleya spp. & orquidea & & & 8 & Orn \\
\hline \multirow[t]{2}{*}{ PASSIFLORACEAE } & Passiflora actinia Hook. & $\begin{array}{l}\text { maracujá-do- } \\
\text { mato }\end{array}$ & & & 2 & $\mathrm{Me}$ \\
\hline & Passiflora edulis Sims. & maracujá & & 2 & & Me/Alim \\
\hline \multirow[t]{3}{*}{ PHYTOLACCACEAE } & Phytolacca dioica L. & ambuseiro & 4 & & & Md \\
\hline & Picrasma crenata (Vellozo) & pau-amargo & & 2 & & $\mathrm{Me}$ \\
\hline & Engler & & & & & \\
\hline \multirow[t]{4}{*}{ PIPERACEAE } & Peperonia sp. & pariparoba & 3 & & & $\mathrm{Me}$ \\
\hline & Piper gaudichaudianum & pariparoba/ & 3 & & 6 & $\mathrm{Me}$ \\
\hline & Kuntze & jaborandi & & & & \\
\hline & $\begin{array}{l}\text { Pothomorphe umbellata L. } \\
\text { Miq. }\end{array}$ & pariparoba & & & 1 & $\mathrm{Me}$ \\
\hline PLANTAGINACEAE & Plantago australis Lam. & tansagen & 1 & 2 & 4 & $\mathrm{Me}$ \\
\hline \multirow[t]{4}{*}{ POACEAE } & $\begin{array}{l}\text { Chusquea mimosa McClure } \\
\text { \& L.B. Sm. }\end{array}$ & cará/criciuma & 2 & 3 & & Orn \\
\hline & $\begin{array}{l}\text { Cortaderia selloana (Schult. } \\
\text { \& Schult. F.) Asch. \& }\end{array}$ & paina & & 1 & & Orn \\
\hline & Graebn. & & & & & \\
\hline & $\begin{array}{l}\text { Merostachys multiramea } \\
\text { Hackel }\end{array}$ & taquara & & 14 & & Md/Orn \\
\hline PODOCARPACEAE & $\begin{array}{l}\text { Podocarpus lambertii } \\
\text { Klotzsch }\end{array}$ & pinheiro-bravo & & 4 & & $\mathrm{Md}$ \\
\hline POLYGONACEAE & Ruprechtia laxiflora Meisn. & marmeleiro & 3 & & & Md \\
\hline PROTEACEAE & Roupala brasiliensis Klotz. & carvalho & & 3 & 4 & Md \\
\hline ROSACEAE & Prunus sellowii Koehne & $\begin{array}{l}\text { pessegueiro- } \\
\text { bravo }\end{array}$ & 8 & & & $\mathrm{Md}$ \\
\hline \multirow[t]{3}{*}{ RUBIACEAE } & Amaioua guianensis Aublet & carvoeiro & & & 2 & Md \\
\hline & $\begin{array}{l}\text { Bathysa meridionalis Smith. } \\
\text { \& Dows. }\end{array}$ & fumeiro & & & 2 & $\mathrm{Me}$ \\
\hline & Cinchona pubescens Vahl. & quina & & 5 & & $\mathrm{Me}$ \\
\hline \multirow[t]{4}{*}{ RUTACEAE } & Balfourodendron & pau-marfin & 18 & & & $\mathrm{Md}$ \\
\hline & riedelianum (Engl.) Engl. & & & & & \\
\hline & $\begin{array}{l}\text { Pilocarpus breviracemosus } \\
\text { Cowan }\end{array}$ & Jaborandi & & & 1 & $\mathrm{Me}$ \\
\hline & $\begin{array}{l}\text { Zanthoxylum rhoifolia } \\
\text { (Lam.) Engl. }\end{array}$ & mamica & 3 & & & Md \\
\hline
\end{tabular}




\begin{tabular}{|c|c|c|c|c|c|c|}
\hline \multirow{2}{*}{ Família botânica } & \multirow{2}{*}{ Nome científico/autor } & \multirow{2}{*}{ Etnoespécie } & \multicolumn{3}{|c|}{ Citações } & \multirow{2}{*}{ Usos } \\
\hline & & & FED & FOM & FOD & \\
\hline SALICACEAE & Casearia sylvestris $\mathrm{Sd}$. & guacatonga & 18 & 10 & 12 & $\mathrm{Me}$ \\
\hline \multirow[t]{3}{*}{ SAPINDACEAE } & $\begin{array}{l}\text { Allophylus edulis (A. St.- } \\
\text { Hil. \& et al.) Radlk }\end{array}$ & vacuum & 2 & 3 & 2 & $\mathrm{Me}$ \\
\hline & Cupania vernalis Camb. & camboatá & 10 & 10 & 10 & $\mathrm{Me}$ \\
\hline & $\begin{array}{l}\text { Matayba elaeagnoides } \\
\text { Radlk. }\end{array}$ & $\begin{array}{l}\text { camboatá- } \\
\text { branco }\end{array}$ & 3 & 2 & & Md \\
\hline SAPOTACEAE & $\begin{array}{l}\text { Chrysophyllum gonocarpum } \\
\text { (Mart. \& Eichl.)Engler }\end{array}$ & aguaí & 6 & & & Md \\
\hline SIMAROUBACEAE & Quassia amara $\mathrm{L}$ & amargo & & 6 & & $\mathrm{Me}$ \\
\hline \multirow[t]{2}{*}{ SOLANACEAE } & $\begin{array}{l}\text { Solanum mauritianum } \\
\text { Scopoli }\end{array}$ & fumeiro & 3 & 1 & & $\mathrm{Me} / \mathrm{Md}$ \\
\hline & Solanum sp. & baga-de-veado & & 3 & & $\mathrm{Me}$ \\
\hline STYRACACEAE & $\begin{array}{l}\text { Styrax leprosus Hook. \& } \\
\text { Arn. }\end{array}$ & carne-de-vaca & 6 & & & $\mathrm{Md}$ \\
\hline SYMPLOCACEAE & $\begin{array}{l}\text { Symplocos uniflora (Pohl) } \\
\text { Bent. }\end{array}$ & sete-sangrias & & 2 & & $\begin{array}{l}\text { continua.. } \\
\mathrm{Me}\end{array}$ \\
\hline TROPAEOLACEAE & $\begin{array}{l}\text { Tropaeolum pentaphyllum } \\
\text { Lam. }\end{array}$ & crem & 2 & & & Me/Alim \\
\hline URTICACEAE & $\begin{array}{l}\text { Urera baccifera (L.) } \\
\text { Gaudich. Ex Wedd. }\end{array}$ & urtigão & 5 & 1 & & $\mathrm{Me}$ \\
\hline \multirow[t]{2}{*}{ VERBENACEAE } & $\begin{array}{l}\text { Aloysia virgata (Ruiz \& } \\
\text { Pav.) Juss. }\end{array}$ & cambara & 3 & 8 & & $\mathrm{Me}$ \\
\hline & $\begin{array}{l}\text { Vitex megapotamica } \\
\text { (Spreng.) Moldenke }\end{array}$ & tarumã & 5 & & 2 & Md \\
\hline WINTERACEAE & Drymis brasiliensis Miers & cataia & & 9 & & $\mathrm{Me}$ \\
\hline TOTAL 67 & Total espécies 160 & & 70 & 68 & 75 & \\
\hline
\end{tabular}

recursos florestais e a empresa de colonização norte-americana Lumber (Southern Brazil Lumber and Colonization Company), que ganhou do governo brasileiro a concessão para exploração de madeira ("imbuia" e "araucária") ao longo da ferrovia que estava construindo.

Segundo Xavier de Carvalho (2006), a grande serraria da empresa Lumber em Três Barras começou a operar em 1911, e desde o início se destacava na atividade madeireira realizada pelos sofisticados processos técnicos que empregava. A serraria tinha capacidade de produção de $300 \mathrm{~m}^{3}$ de madeira serrada por dia, e empregava cerca de 800 trabalhadores, na maioria imigrantes ou seus descendentes. Numa época em que inexistiam caminhões para o transporte das toras até as serrarias, a Lumber investiu em construção de ferrovias particulares dentro de suas propriedades, e contava com grandes guinchos movidos a vapor para puxar as toras distantes até 300 metros da ferrovia.
$\mathrm{Na}$ região da Floresta Ombrófila Mista destaca-se também uma forte relação com o "araucária" (Araucaria angustifolia) através da comercialização do pinhão e comercialmente com a "erva-mate" (Ilex paraguariensis), sendo este um recurso muito importante desde o final do século XIX na região, principalmente ligado à exportação para a Argentina, Paraguai e Uruguai.

A fase histórica de predomínio econômico da "erva-mate" na região representou para os agricultores um papel significativo dessa cultura na indução de uma definição de uso da terra motivado pela necessidade de subsistência. Segundo Novak \& Fajardo (2008), nas chamadas "matas limpas" onde ocorria a "erva-mate", as frutíferas silvestres, os "pinheiros" (Araucaria angustifolia) e as gramíneas, foi também onde se desenvolveu o criadouro Faxinal, denominado localmente de caíva.

Segundo os agricultores, o faxinal era 
A. Siminski et al., Recursos Florestais Nativos e a Agricultura Familiar em Santa Catarina, Brasil

Tabela 3. Número médio de citação para espécies presentes em três formações florestais de Santa Catarina, em grupos de informantes, acrescido do valor de diversidade do informante (VDI*).

\begin{tabular}{|c|c|c|c|c|c|c|c|}
\hline \multirow[t]{2}{*}{ Categoria } & \multirow[t]{2}{*}{ Grupos } & \multicolumn{3}{|c|}{$\begin{array}{l}\text { Número médio de } \\
\text { espécie citadas }\end{array}$} & \multicolumn{3}{|c|}{ VDI } \\
\hline & & FED & FOD & FOM & FED & FOD & FOM \\
\hline \multirow{4}{*}{ Idade } & $40-50$ anos & 22 & 27 & 24 & $0,30 \pm 0,06 \mathrm{~A}$ & $0,34 \pm 0,03 \mathrm{~A}$ & $0,32 \pm 0,08 \mathrm{~A}$ \\
\hline & $51-60$ anos & 21 & 27 & 23 & $0,30 \pm 0,09 \mathrm{~A}$ & $0,34 \pm 0,04 \mathrm{~A}$ & $0,31 \pm 0,03 \mathrm{~A}$ \\
\hline & 61- 70anos & 19 & 18 & 23 & $0,26 \pm 0,07 \mathrm{~A}$ & $0,23 \pm 0,06 \mathrm{~A}$ & $0,32 \pm 0,03 \mathrm{~A}$ \\
\hline & $>70$ anos & 14 & - & - & $0,23 \pm 0,12 \mathrm{~A}$ & - & - \\
\hline \multirow{2}{*}{ Município** } & A & 25 & 24 & 22 & $0,35 \pm 0,04 \mathrm{~A}$ & $0,30 \pm 0,05 \mathrm{~A}$ & $0,31 \pm 0,03 \mathrm{~A}$ \\
\hline & B & 15 & 25 & 24 & $0,20 \pm 0,05 B$ & $0,31 \pm 0,06 \mathrm{~A}$ & $0,33 \pm 0,05 \mathrm{~A}$ \\
\hline \multirow{4}{*}{$\begin{array}{l}\text { Tamanho da } \\
\text { propriedade }\end{array}$} & Até 20 hectares & 21 & 23 & 22 & $0,30 \pm 0,07 \mathrm{~A}$ & $0,29 \pm 0,02 \mathrm{~A}$ & $0,30 \pm 0,02 \mathrm{~A}$ \\
\hline & 21-30 hectares & 21 & 24 & 24 & $0,30 \pm 0,08 \mathrm{~A}$ & $0,31 \pm 0,07 \mathrm{~A}$ & $0,33 \pm 0,06 \mathrm{~A}$ \\
\hline & $31-40$ hectares & 21 & 25 & - & $0,30 \pm 0,09 \mathrm{~A}$ & $0,32 \pm 0,06 \mathrm{~A}$ & - \\
\hline & $>40$ hectares & 14 & 24 & 23 & $0,19 \pm 0,08 \mathrm{~A}$ & $0,31 \pm 0,06 \mathrm{~A}$ & $0,32 \pm 0,03 \mathrm{~A}$ \\
\hline \multirow{5}{*}{$\begin{array}{c}\text { \% de área da } \\
\text { propriedade com } \\
\text { mata }\end{array}$} & Até $20 \%$ & 19 & 24 & 26 & $0,27 \pm 0,08 \mathrm{~A}$ & $0,31 \pm 0,05 \mathrm{~A}$ & $0,31 \pm 0,03 \mathrm{~A}$ \\
\hline & 21 a $30 \%$ & 21 & 26 & 20 & $0,30 \pm 0,10 \mathrm{~A}$ & $0,32 \pm 0,09 \mathrm{~A}$ & $0,33 \pm 0,06 \mathrm{~A}$ \\
\hline & 31 a $40 \%$ & 24 & 23 & 21 & $0,24 \pm 0,10 \mathrm{~A}$ & $0,29 \pm 0,02 \mathrm{~A}$ & $0,31 \pm 0,03 \mathrm{~A}$ \\
\hline & 41 a $60 \%$ & 12 & 27 & - & $0,25 \pm 0,08 \mathrm{~A}$ & $0,34 \pm 0,07 \mathrm{~A}$ & - \\
\hline & $>60 \%$ & - & 22 & - & & $0,29 \pm 0,04 \mathrm{~A}$ & - \\
\hline \multicolumn{2}{|c|}{ Total de citações } & 71 & 79 & 73 & & & \\
\hline
\end{tabular}

*VDI - Valor de diversidade do informante = número de citações de cada informante, dividido pelo número total de citações. Médias seguidas por letras diferentes na coluna diferem significativamente pelo teste de Kruskal-Wallis a 5\% probabilidade. Para município foi usado teste de Kolmogorov-Smirnov a $5 \%$ probabilidade. $\mathrm{X}=$ média; D.P= desvio padrão. FED: Floresta Estacional Decidual, FOD: Floresta Ombrófila Densa, FOM: Floresta Ombrófila Mista. Descrição municípios: FED: A- Anchieta, B-Concórdia; FOD: A- Garuva, B- São Pedro de Alcântara; FOM: A- Caçador, B- Três Barra.

todo cercado com "ripões", normalmente de imbuía, ou por uma grande vala, onde também era plantado o "caraguatá" (Bromelia antiacantha), impedindo que os animais que ficavam soltos na pastagem avançassem às terras de lavouras, "terras de plantá". A roçada da caíva facilitava a pastagem dos animais e a colheita de "erva-mate". O uso da mão-de-obra nas roçadas foi se intensificando de acordo com o desenvolvimento da indústria da "erva-mate" e a valorização do produto no mercado, até a década de 1930.

Além da "erva-mate", destacou-se um grande número de espécies associadas a diversos usos na propriedade, como medicinal, energético (lenha), ornamental, alimentar, fibras e madeiras (palanques, cabo de ferramentas). Dentre essas espécies, receberam bastante destaque pelo número de citações a "bracatinga" (Mimosa scabrella), "espinheira-santa" (Maytenus ilicifolia), "uvaia" (Eugenia pyriformis), "caraguatá" (Bromelia antiacantha), "taquara" (Merostachys multiramea), "pitanga" (Eugenia uniflora), "carqueja" (Baccharis trimera), "butiá" (Butia eriospatha), "xaxin" (Dicksonia sellowiana), "pimenteira" (Capsicodendron dinisii), "cedro"(Cedrela fissilis), "guacatonga" (Casearia sylvestris), "araçá" (Psidium cattleyanum), e "goiaba-do-mato" (Acca sellowiana) (Tabela 2)

Floresta Ombrófila Densa. Incluindo os municípios de Garuva e São Pedro de Alcântara. Em Garuva a intensa exploração de recursos florestais esteve associada à demanda energética das indústrias da região (Joinville e Curitiba), principalmente nas décadas de 1950 e 1960. Nesse caso, as áreas eram desmatadas e algumas madeiras mais nobres comercializadas, mas a maior parte era transformada em carvão. O carvão era usado com fins energéticos diretos 
nas caldeiras ou no processo produtivo do aço, nas indústrias metalúrgicas da região.

Por sua vez, no município de São Pedro de Alcântara os recursos florestais estavam bastante associados ao aproveitamento madeireiro e a formação das roças, principalmente para o cultivo da "cana-de-açúcar" e "mandioca". Entre as principais espécies estão as "canelas" (Nectandra spp. e Ocotea spp.), o "jacatirãode-copada" (Miconia cinnamomifolia), "cedro" (Cedrela fissilis), "licurana" (Hyeronima alchorneoides) e o "jacatirão" (Tibouchina pulchra).

Entre os usos não madeireiros de espécies na região da Floresta Ombrófila Densa, destaca-se com grande importância o "palmito" (Euterpe edulis), com um histórico de uso bastante intenso em toda região. Entre outros produtos estão as plantas medicinais como a "guaçatonga"(Caseariasylvestris), "espinheirasanta" (Zollernia ilicifolia), as alimentícias como a "guabiroba" (Campomanesia xanthocarpa), "araçá" (Psidium cattleyanum), "pitanga" (Eugenia uniflora) e o "bacupari" (Garcinia gardneriana), plantas fibrosas como o "cipó-imbé" (Philodendron corcovadense), e ornamentais como a "guaricana" (Geonoma gamiova), além de diversas espécies de orquídeas e bromélias.

\section{O uso atual dos recursos florestais}

Atualmente, o uso dos recursos florestais nativos está associado fortemente ao consumo na propriedade, especialmente para fins energéticos (lenha) e o consumo esporádico de frutas e plantas medicinais, a exemplo do que foi destacado por Caffer (2005), que identificou 338 espécies utilizadas por agricultores na região de Caçador, dentre as quais $60 \%$ plantas nativas, e por Zuchiwschi (2008), que identificou 132 espécies com uso região de Anchieta.

Apesar do uso de subsistência predominar, alguns produtos ainda possuem contribuição direta na obtenção de renda da propriedade. A exploração da "erva-mate", nas regiões de Anchieta, Concórdia, Caçador e Três Barras, é um exemplo dessa relação. Mesmo com o forte incentivo à monocultura em ambientes abertos na década de 1980, os agricultores que possuem ervais nativos ou sob sombreamento representam uma porção significativa do volume extraído e comercializado de ervamate. A "erva-mate" continua sendo o principal produto não-madeireiro no Sul do Brasil de acordo com o IBGE (2006). Segundo os entrevistados, a "erva-mate" oriunda de ervais nativos tem recebido maior remuneração por quantidade do produto, já que os compradores e consumidores do produto alegam que a erva nativa sombreada apresenta "gosto mais suave" que a erva cultivada a pleno sol.

Neste mesmo contexto, a "araucária" foi historicamente utilizada para geração de renda por meio dos produtos obtidos da sua madeira, polpa para celulose, nó-de-pinho e o pinhão. $O$ pinhão continua a ser uma fonte de alimento tradicional nas residências em todos os municípios pesquisados, destacandose como um recurso de grande importância na subsistência de comunidades rurais. Ao mesmo tempo, tem sido uma alternativa de renda significativa para as famílias que vivem na região de ocorrência da espécie, a exemplo do que foi relatado por Vieira da Silva (2006) na região de Caçador. Dos agricultores entrevistados nos municípios de Caçador e Três Barras, 48\% comercializam pinhões eventualmente, e $86 \%$ os distribuem a parentes e conhecidos.

$\mathrm{Na}$ região de Garuva, dois produtos têm se destacado comercialmente nos últimos anos: a polpa dos frutos do "palmiteiro" (Euterpe edulis), conhecida como açaí, e o uso da fibra do "cipó-imbé" ou "cipó-preto" (Philodendron corcovadense). A iniciativa de uso dos frutos do "palmiteiro" na região foi impulsionada com a implantação da primeira unidade de processamento comercial dos frutos do "palmiteiro" para a fabricação do açaí em Garuva, no ano de 2004, sendo criada nesse mesmo ano a marca "Açaí Mata Atlântica". Também uma parceria entre a ONG Vida Verde (Joinville-SC) e a Empresa de Pesquisa Agropecuária e Extensão Rural do Estado de Santa Catarina (Epagri) promoveu encontros com agricultores com o objetivo de incentivar a produção de açaí (Mac Fadden, 2005).

Por sua vez, o uso do "cipó-imbé" na região vem sendo tradicionalmente explorado há gerações. Segundo dados de Tonicelo (2004), cerca de 200 famílias em Garuva se dedicam 
direta ou indiretamente à extração e manufatura do "cipó-imbé" para artesanato. Esse artesanato é feito por famílias de pequenos produtores rurais, que complementam a renda com essa atividade, mas que em alguns casos dependem unicamente da renda do trabalho com cipó. Apartir de 2004, foram então estabelecidas diversas parcerias, formando-se o Núcleo CipóImbé, que vem buscando articular ações nas áreas de manejo sustentável, design integral e economia solidária (Tonicelo \& al., 2007).

Diversos outros recursos florestais nativos utilizados pelos agricultores são considerados como potenciais para uso econômico e podem ser utilizados como fontes de renda alternativa. Entre as espécies listadas, 71 (44\%) foram citadas como espécies potenciais para uso econômico pelo projeto do Ministério do Meio Ambiente (MMA/PROBIO) conhecido como "Plantas para o Futuro - Região Sul" (Coradin $\&$ al., 2011). Porém, como destacam Fantini \& Siminski (2007), é necessário investimento para gerar e disponibilizar tecnologia de uso sustentável dos recursos florestais nativos, aliado a avanços na regulamentação dos usos, para que seja viável o uso comercial destes recursos. Estas espécies podem ser trabalhadas como elementos de valor da floresta e de valorização dos remanescentes para os agricultores familiares.

Analisando a questão no Estado de Santa Catarina, sob um ponto de vista sistêmico, Siminski (2009) sugere que a restrição ao uso e manejo dos recursos como estratégia de promover a preservação florestal tem resultado em um ciclo de retroalimentação oposto ao desejado, ou seja, a existência de ecossistemas florestais nativos passou a ser encarada como inconveniente e não como oportunidade pelos agricultores e produtores rurais para a conservação e o uso de espécies nativas.

O abandono do uso, por sua vez, pode provocar perda do conhecimento associado a estas espécies, processo esse já identificado por Zuchiwschi \& al. (2010) na região de Anchieta, onde os dados mostram que existe um processo gradual de perda das condições de transmissão do conhecimento tradicional local com risco de erosão do conhecimento acumulado.

\section{Conclusões}

As áreas de formações florestais passaram por momentos onde se configuraram diversas perspectivas quanto ao aproveitamento de seus recursos e confundiram-se muitas vezes com a própria trajetória de ocupação do território. Os resultados revelaram que esses agricultores possuem um amplo conhecimento a respeito do potencial de uso das espécies nativas da região, abrangendo parte significativa das espécies da flora local.

$\mathrm{O}$ uso efetivo atual dos recursos florestais se destina principalmente ao autoconsumo nas unidades de produção, com destaque para o uso madeireiro, medicinal e alimentício. Apesar disso, o uso madeireiro têm sido reduzido nos últimos anos devido, principalmente, a limitações ao acesso legal às espécies florestais nativas.

O manejo de formações florestais para a produção de madeira e outros produtos florestais é considerado, não raro, uma ameaça à conservação ambiental na região Sul. Entretanto, tornar os remanescentes florestais economicamente viáveis pode revelar-se uma valiosa alternativa para os agricultores familiares da região do Bioma Mata Atlântica, há décadas confrontados com sucessivas crises da agricultura moderna.

As atuais políticas de conservação dos recursos florestais têm se manifestado na forma de novas legislações, que invariavelmente aumentam o rol do que não é permitido fazer, uma estratégia que apenas aprofunda a distância de opiniões existente entre agricultores e conservacionistas.

Apesar disso, os agricultores da região reconhecemaimportância das florestasenquanto possíveis promotoras de bens e serviços, mas mostram-se inseguros com possibilidades de uso que não fazem parte das suas estratégias de sobrevivência, construídas por relações de interação e/ou exploração, equese estabeleceram desde a chegada de seus antepassados. Adicionalmente, esses agricultores demonstram deter grande conhecimento sobre as espécies e o seu ambiente, estes fatores indicam que eles são atores indispensáveis na proposição de qualquer estratégia que priorize a conservação efetiva dos remanescentes florestais. Integrar 
esses conhecimentos é extremamente importante para a manutenção, a sobrevivência e o desenvolvimento dessas populações e, consequentemente, para a conservação da floresta em longo prazo.

\section{Bibliografia}

BALDAUF, C.; HANAZAKI, N. \& REIS, M. S. 2007. Caracterização etnobotânica dos sistemas de manejo de samambaia-preta (Rumohra adiantiformis (G.Forst) Ching- Dryopteridaceae) utilizados no sul do Brasil. Acta Botanica Brasilica 21: 823-834.

BERKES, F. \& FOLKE, C. 1998. Linking ecological and social systems for resilience and sustainability. In: Linking ecological and social systems: management practices and social mechanisms for building resilience. Cambridge Univesity Press, Cambried, England, pp. 1-25.

BERNARD, H.R. 1995. Research methods in anthropology: qualitative and quantitative approaches. 2nd ed. Walnut Creek, Altamira Press. $585 \mathrm{pp}$.

BRASIL. Lei ${ }^{\circ}$. 4.771, de 15 de setembro de 1965. Institui o Novo Código Florestal. In: Lex: SANTA CATARINA (Estado). 2002. Leis, decretos, etc. Coletânea da legislação ambiental aplicável no estado de Santa Catarina. Florianópolis: FATMA, pp.429-433.

BYG, A. \& BALSLEV, H. 2001. Diversity and use of palms in Zahamena, eastern Madagascar. Biodiversity and Conservation 10: 951-970.

CAFFER, M.M. 2005. Caracterização do conhecimento de populações locais sobre a diversidade de recursos genéticos vegetais em remanescentes da Floresta Ombrófila Mista, na região do Contestado em Santa Catarina. Dissertação (Mestrado em Recursos Genéticos Vegetais) - Universidade Federal de Santa Catarina, $136 \mathrm{pp}$.

CARVALHO, E.B. \& NODARI, E.S. 2007. A Percepção na Transformação da Paisagem: Os Agricultores no Desflorestamento de Engenheiro Beltrão - Paraná, 1948-1970. História 26, 2: 269-287.

CHANG, M. Y. 1988. Sistema Faxinal: uma forma de organização camponesa em desagregação no centro-sul do Paraná. Boletim Técnico (IAPAR) 22, $124 \mathrm{pp}$.

COLWELL, R. K.; MAO, C.X. \& CHANG, J. 2004. Interpolating, extrapolating, and comparing incidence-based species accumulation curves. Ecology 85: 2717-2727.

- 2006. Estimates: statistical estimation of species richness and shared species from samples. Version 8. Disponível em: purl.oclc.org/estimates.

CORADIN, L.; SIMINSKI, A.; REIS, A. (Ed.). 2011.
Espécies nativas da flora brasileira de valor econômico atual ou potencial: plantas para o futuro - Região Sul. Brasília: MMA, 934 pp.

DALMORA, E. 2004. O papel da agricultura familiar no processo de conservação da Mata Atlântica em Santa Catarina. modos de apropriação e transformações no sistema de gestão ambiental na década de 1990 . Tese (Pos-graduação Interdisciplinar em Ciências Humanas, ) - Universidade Federal de Santa Catarina - UFSC, Florianópolis, 346 pp.

DESLANDES, S.F.; NETO, O.C.; GOMES, R. \& MINAYO, M.C. 1994. Pesquisa social: teoria, método e criatividade. Petrópolis: Vozes, 80 pp.

DIEGUES, A.C. 2000. Etnoconservação da natureza: enfoques alternativos. In: DIEGUES, A.C. (org.). Etnoconservação: novos rumos para a proteção da natureza nos trópicos. São Paulo: Hucitec, NUPAUB - USP, pp. 1-46.

FANTINI, A.C. 1999. Palm Heart (Euterpe edulis) Production and Management in the Brazilian Mata Atlântica. Madison: University of Wisconsin. Tese (Doutorado em Ciências Florestais) - University of Wisconsin, 127pp.

— \& SIMINSKI, A. 2007. De agricultor a "agricultor silvicultor": um novo paradigma para a conservação e uso de recursos florestais no Sul do Brasil. Agropecuária Catarinense 20: 16-18.

FREUDENBERGER, K. S. 1994. Tree and Land Tenure: rapid appraisal tools. Rome: FAO. 87 pp.

GADGIL, M.; BERKES, F. \& FOLKE, C. 1993. Indigenous knowledge for biodiversity conservation. Ambio 22: 151-156.

GOTELLI, N. \& COLWELL, R. K. 2001. Quantifying biodiversity: Procedures and pitfalls in the measurement and comparison of species richness. Ecology Letters 4: 379-391.

GUIVANT, J.S. 1997. Heterogeneidade de conhecimentos no desenvolvimento rural sustentável. Cadernos de ciência e tecnologia (Embrapa/Brasilia) 14, 3: 411448.

HANAZAKI, N. 2003. Comunidades, conservação e manejo: o papel do conhecimento ecológico tradicional. Biotemas 16: 23-47.

HOFFMAN, B. \& GALLAHER, T. 2007. Importance indices in ethnobotany. Ethnobotany Research \& Applications 5: 201-218.

IBGE. 2006. Produção da Extração Vegetal e da Silvicultura. Rio de Janeiro, 21: 1-45.

ICEPA - Instituto Cepa/SC. 2005. Levantamento Agropecuário Catarinense: resultados preliminares. Florianópolis. SC, CD-ROM.

JAIN, S.K. 2000. Human aspects of plant diversity. Economic Botany 54, 4: 459-470.

MAC FADDEN, J. 2005. A produção de açaí a partir do processamento dos frutos do palmiteiro (Euterpe edulis Martius) na Mata Atlântica. Dissertação 
(Mestrado Agroecossistemas, UFSC), Florianópolis, SC. 100 pp.

NODARI, E. 1999. A renegociação da etnicidade no Oeste de Santa Catarina (1917-1954). Tese (doutorado). Pontifícia Universidade Católica do Rio Grande do Sul. Porto Alegre. 322 pp.

NOVAK, R. \& FAJARDO, S. 2008. Desintegração e resistência do sistema faxinal em Itapará - Irati PR. UNICENTRO - Revista Eletrônica Lato Sensu Ed.4. Disponível em: http://web03.unicentro.br/ especializacao/Revista_Pos/P\%C3\%A1ginas/4\%20 Edi\%C3\%A7\%C3\%A3o/Humanas/PDF/6-Ed4 CH-Desinte.pdf

PERONI, N. \& MARTINS, P.S. 2000. Influência da dinâmica agrícola itinerante na geração de diversidde de etnovariedades cultivadas vegetativamente. Interciência 25, 1: 22-29.

—; BEGOSSI, A. \& HANAZAKI, N. 2008. Artisanal fishers ethnobotany: from plant diversity use to agrobiodiversity management. Environment, Development and Sustainability 10: 623-637.

RAMOS, G.C.P. 2006. A formação do território de Santa Catarina com base na concessão de terras públicas. Dissertação (Pós-graduação em Engenharia Civil), Universidade Federal de Santa Catarina. 281 pp.

REIS. M.S.; FANTINI, A.C.; NODARI, R.O.; REIS, A.; GUERRA, M.P. \& MANTOVANI, A. 2000. Management and conservation of natural populations in Atlantic Rain Forest: The case study of Palm Heart (Euterpe edulis Martius). Biotropica 32, 4b: 894-902.

- 2006. Extrativismo no Sul e Sudeste do Brasil: Caminhos para a sustentabilidade sócioambiental. In: KUBO, R.R; BASSI, J.B.; SOUZA, G.C.; ALENCAR, N.L.; MEDEIROS, P.M. \& ALBUQUERQUE, U.P. (org.). Atualidades em Etnobiologia e Etnoecologia 3: 117-128.

SANTOS, M.P.R.T. 2004. Vida e trabalho na floresta: Uma análise da interação entre imigrantes e a floresta nas colônias do vale do Itajaí e norte de Santa Catarina durante a segunda metade do século XIX. Dissertação (Pós-graduação em História), Universidade Federal de Santa Catarina. 183 pp.

SEIXAS, C. S. 2005. Abordagens e técnicas de pesquisa participativa em gestão de recursos naturais. In VIEIRA, P. F.; BERKES, F. \& SEIXAS, C. S. Gestão integrada e participativa de recursos naturais: conceitos, métodos e experiências. Florianópolis: Secco/APED, pp. 73-105.

SIMINSKI, A. 2004. Formações florestais secundárias como recurso para o desenvolvimento rural e a conservação ambiental no litoral de Santa Catarina. Dissertação (Mestrado em Recursos Genéticos Vegetais) - Universidade Federal de Santa Catarina - UFSC, Florianópolis, 117 pp.

— \& FANTINI, A. C. 2007. Roça-de-toco: uso de recursos florestais e dinâmica da paisagem rural no litoral de Santa Catarina. Ciência Rural 37: 01-10.

2009. A floresta do futuro: conhecimento, valorização e perspectivas de uso das formações florestais secundárias no Estado de Santa Catarina. Florianópolis, SC, Tese (Doutorado) - Universidade Federal de Santa Catarina, 148 pp.

TONICELO, R.H.S.. 2004. Diagnóstico para a Aplicação do Design de Sistema-Produto no Artesanato de fibra de Cipó Imbé da Comunidade de Artesãos de Garuva. Trabalho de Conclusão de Curso, Bacharelado em Design Industrial - Departamento de Design / CEART / UDESC. 101 pp.

; ANTUNES, D. L. ; SIMOES, M. B. A. \& ZAMBONIM, R. M. 2007. Sustentabilidade na Cadeia Produtiva do Artesanato de Cipó Imbé: O Enfoque Participativo no Processo de Manejo e Design.. In: I Encontro de Sustentabilidade do Vale do Itajaí, 2007, Balneário Camboriú. Anais do I ENCONTRO DE SUSTENTABILIDADE DO VALE DO ITAJAII. Balneário Camboriú : UNIVALI. pp 2017-2082.

TUXILL, J. \& NABHAN, G.P. 2001. People, plants and protected areas. A guide to in situ management. Earhscan Publications, London, 277 pp.

VIEIRA DA SILVA, C. 2006. Aspectos da obtenção e comercialização de pinhão na região de Caçador - SC. Florianópolis. Dissertação (Mestrado). Universidade Federal de Santa Catarina, Programa de Pós-Graduação em Recursos Genéticos Vegetais. $111 \mathrm{pp}$.

XAVIER de CARVALHO, M.M. 2006. Atravessando limites: o desmatamento no Médio Iguaçu (18901945). 2006. Dissertação (Mestrado em História) - Universidade Federal de Santa Catarina. 201 pp.

ZUCHIWSCHI, E. 2008. Florestas Nativas na Agricultura Familiar de Anchieta, Oeste de Santa Catarina: conhecimentos, usos e importância. Dissertação. (Mestrado em Recursos Genéticos Vegetais). Universidade Federal de Santa Catarina, Florianópolis. 186 pp.

; FANTINI, A. C. ; ALVES, A. C. \& PERONI, N. 2010. Limitações ao uso de espécies florestais nativas pode contribuir com a erosão do conhecimento ecológico tradicional. Acta Botanica Brasilica 24: 270-282.

Original recibido el 25 de julio de 2011; aceptado el 9 de diciembre de 2011. 
